\title{
VERFASSUNG UND VERWALTUNG
}

\author{
IN SÜDWESTDEUTSCHEN STÄDTEN
}

\author{
DER FRÜHEN NEUZEIT
}

von Franz Quarthal

Der südwestdeutsche Raum zeichnet sich unter den Landschaften des alten deutschen Reiches durch zwei Eigenschaften aus: Zum einen ist er - neben Franken — die politisch am vielfältigsten gegliederte Landschaft, zum anderen ist er eine der Regionen des alten deutschen Reiches mit der größten Städtedichte ${ }^{1}$.

Von den rund 300 Ständen des deutschen Reiches um 1800 befanden sich etwa ein Drittel, nämlich 97, innerhalb des Schwäbischen Kreises, von denen die vier geistlichen Fürsten - die Bischöfe von Augsburg und Konstanz, der gefürstete Abt von Kempten und der Propst von Ellwangen -, die 14 weltlichen Fürsten - um die bedeutendsten zu nennen: die Herzöge von Württemberg, die Fürsten von Fürstenberg, von Hohenzollern und von Öttingen sowie die Markgrafen von Baden — und einige der Grafen und Herren über eine beachtliche Anzahl landsässiger Städte herrschten. Von den 51 Reichsstädten, die um 1800 bestanden, lagen 31 innerhalb des Schwäbischen Kreises ${ }^{2}$. Dazu kamen noch 30 Städte des Hauses Habsburg, die als Teil des Österreichischen Kreises im Schwäbischen Kreis eingebettet lagen. Neben den 31 Reichsstädten zählte man ferner rund 140 landsässige Städte innerhalb des Schwäbischen Kreises, von denen der größere Teil - nämlich 60 - zum Herzogtum Württemberg gehörte ${ }^{3}$. Wolfgang Leiser hat vor wenigen Jahren am Beispiel einiger kleinerer Territorien sichtbar machen können, daß der Anteil an der Gesamtbevölkerung, der in den Städten lebte, zu Ende des 18. Jahrhunderts zwischen $18 \%$ und $25 \%$ schwankte ${ }^{4}$; für Württemberg und Vorderösterreich, zu deren

\footnotetext{
'K.S. BADER, Der deutsche Sudwesten in seiner territorialstaatlichen Entwicklung. Sigmarıngen ${ }^{2} 1978$, Historischer Atlas von Baden-Wurttemberg, hg v. der Kommission für geschichtliche Landeskunde in Baden-Württemberg, Stuttgart 1982-1988. Karte und Erlauterungen VI,9. Reichskreıse und Schwäb1sche Kreisstände um 1800 Karte und Erläuterungen VI,13. Herrschaftsgebıete und Ämterglıederung in Südwestdeutschland 1790. Vgl. auch die Darstellung von K. BiedermanN, Deutschland im 18 Jahrhundert 1 (ND der 2. Aufl., Leipzig 1880), Aalen 1969, S. 9-12.

2E. HölzLE, Der deutsche Südwesten am Ende des alten Reiches. Geschıchtliche Karte des reıchsdeutschen und benachbarten Gebiets, Stuttgart 1938, Beiwort, S. 1-91, K.S. BADER, Die Reichsstadte des schwäbischen Kreises am Ende des alten Reiches, in: Ulm und Oberschwaben 32 (1951), S.52.

${ }^{3}$ Diesen rund 200 Städten in Südwestdeutschland standen vergleıchsweıse in Bayern nur 34 Stadte und 90 Märkte gegenüber ( $R$. Heydenrelter, Die Behördenreform Maxımılıans 1 , in: Wittelsbach und Bayern, Ausstellungskatalog, Bd. 2,1, München 1980, S. 246).

${ }^{4}$ W. Leiser, Die Stadt im suddeutschen Kleınstaat des Ancien Régıme, in. Stadtewesen und Merkant1lismus in Mitteleuropa, hg. v. V. Press, Koln, Wien 1983, S. 111-134.
} 
Herrschaft nahezu zwei Drittel der landsässigen Städte innerhalb des Schwäbischen Kreises gehörten, lag der Anteil der städtischen Einwohner nahe bei $25 \%{ }^{5}$. In Bayern lag dieser Wert im 18. Jahrhundert deutlich niedriger, nämlich nur bei $18 \%{ }^{6}$. Für frühere Zeiten ist es kaum möglich, flächenübergreifende Zahlenangaben zu ermitteln. Angesichts der Tatsache, daB nach 1648 die wirtschaftliche Expansion und das Bevölkerungswachstum im ländlichen Raum größer war als in den Städten, wird man für das 16. und 17. Jahrhundert eher noch einen höheren städtischen Bevölkerungsanteil annehmen dürfen als für das 18. Jahrhundert ${ }^{7}$.

Innerhalb dieser durch das Band des Stadtrechts zusammengehaltenen Siedlungen bestanden selbstverständlich größere Unterschiede: Zwischen den Zwergstädten Tengen dem „Städtlin“, Obernau dem „Städtlin“, Hayingen mit jeweils wenigen zehn oder zwanzig Häusern ${ }^{8}$, den Residenzstädten Mannheim, Karlsruhe und Ludwigsburg, Exulantenstädten wie Frankenthal, Bergbaustädten wie Freudenstadt oder den Reichsstädten Ulm und Augsburg lagen Welten ${ }^{9}$.

Wenn im folgenden Generalisierungen versucht werden sollen, so geschieht dies durchaus im Bewußtsein von Vergröberung und Vereinfachung. $\mathrm{Zu}$ Recht hat Otto Borst, einer der Kenner der südwestdeutschen Städtelandschaft, unterstrichen, $\mathrm{da} B$ trotz aller gemeinsamen Tendenzen jede Stadt eine Individualität sei und als solche interpretiert werden müsse ${ }^{10}$.

Als Typus wird man eine landsässige schwäbische Stadt der Neuzeit als eine Siedlung von etwa 3.000 Einwohnern mit einem wenig spezialisierten Gewerbe und einer Mittelpunktsfunktion für einen Nahraum von etwa $20 \mathrm{~km}$ Radius ansehen dürfen, für die Fernhandel eine geringe Rolle spielte und in der ein beträchtlicher Teil der Einkommen im agrarischen Bereich erzielt wurde ${ }^{11}$. Die Reichsstädte waren zumeist größer, stärker exportorientiert und vielfach verkehrsgünstiger gelegen. In ihrer städtebaulichen Substanz sind sie in der Regel reicher als landsässige Städte, und dies gilt besonders für die Periode des 17. und 18. Jahrhunderts, die man gemeinhin als Zeit des Niedergangs der Reichsstädte versteht ${ }^{12}$.

\footnotetext{
${ }^{5}$ F. QUARTHAL, Landstände und landständisches Steuerwesen in Schwäbısch-Österreıch (Schriften zur südwestdeutschen Landeskunde), Stuttgart 1980, S. 319; K.-O. BULL, Die württembergischen Steuerlısten von 1544/45 und ihre Bedeutung für die Sozial-und Wirtschaftsgeschichte, in: W. EHBRECHT (Hg.), Voraussetzungen und Methoden geschichtlicher Städteforschung, Köln/Wien 1979. S 103, vgl. auch wettere Angaben bei K. GerTEIS, Die deutschen Städte in der frühen Neuzeit. Zur Vorgeschichte der 'bürgerlıchen Welt', Darmstadt 1986. S. 59f.

${ }^{6} \mathrm{~W}$. STÖRMER. Wirtschaft und Bürgertum in den altbayerischen Städten unter dem zunehmenden absolutıstischen EinfluB des Landesfürsten, in: W. Rausch (Hg.), Die Städte Mitteleuropas im 17 und 18. Jahrhundert (Beıträge zur Geschıchte der Städte Mitteleuropas 5), Lınz 1981, S 237-266, hıer S. 238.

'Quarthal, wie Anm. 5, S. 319.

${ }^{8} \mathrm{H}$. RaISCH, Die Zwergstädte Württembergs. Begriff und Verbreitung, in: Berichte zur deutschen Landeskunde 40 (1968). S. 36-58.

${ }^{9} \mathrm{Zur}$ Typologie neuzeitlıcher Gründungsstädte in Südwestdeutschland vgl. J. Sybow, Städte im deutschen Sudwesten. Ihre Geschıchte von der Römerzeıt bis zur Gegenwart, Stuttgart 1987. S. 175-179: vgl auch die Literaturzusammenstellung bei GerTEis, wie Anm. 5, S. 189-191

${ }^{10} \mathrm{O}$. Borst, Zur Verfassung und Staatlichkeit oberdeutscher Reichsstädte am Ende des alten Reıches. in Esslinger Studien 10 (1964), S. 106-194, hier S. 106; ebenso K.S. BADER, Die oberdeutsche Reichsstadt im alten Reich, in. Esslınger Studien 11 (1965). S. 23-42, hier S. 25; DERS., wie Anm. 2. S 247-270

IIW Leiser, wie Anm. 4, S 119-124; für Baiern ähnlich Störmer, wie Anm. 6, S 245.

$12 \mathrm{Vgl}$. Gerteis, wie Anm. 6. S. 2f.; mit sehr differenzierter Würdigung Borst, wie Anm 10. S. 106-110. zusammenfassend zitiert ailtere Urteile A. LAUfs, Die Verfassung und Verwaltung der Stadt Rottweil 1650-1806 (VKomLk in Baden-Württemberg B 22), Stuttgart 1963, S.1.
} 
Die Zeit zwischen der Mitte des 16. und dem Ende des 18. Jahrhunderts bildete sowohl für die Geschichte der Reichs- als auch für die der landsässigen Städte Südwestdeutschlands eine Einheit. Bei den Reichsstädten markieren die Eingriffe Kaiser Karls V. und seines Rates Heinrich $\mathrm{HaB}$ (1547-1556), mit denen der Anteil der Zünfte am Stadtregiment beschnitten und die Position der altgläubigen Geschlechter gestärkt wurde, eine deutliche Zäsur ${ }^{13}$. Man hat damit die Verknöcherung des Zunftwesens und eine Erstarrung der Magistratsverwaltungen verbunden, mit der die oligarchisch-aristokratische Spätphase reichsstädtischer Verfassungsgeschichte eingeleitet wurde ${ }^{14}$.

Neuere Forschungen der letzten drei Jahrzehnte sehen dies differenzierter. Zum einen hat es kaiserliche Eingriffe in reichsstädtische Verfassungszustände bereits früher und häufiger gegeben, als man dies in älteren Arbeiten gesehen hat. Zum anderen findet sich das Phänomen der Erstarrung der Magistratsverfassung zu einer oligarchisch-aristokratischen Form auch dort, wo Karl V. nicht eingegriffen hat. In Rottweil, wo die Zunftverfassung voll erhalten geblieben ist, gerierte sich der Magistrat der Bürgerschaft gegenüber nicht anders, als dies in Städten mit patrizischem Regiment geschah ${ }^{15}$. Schließlich sieht man heute auch die von der Verfassungsnorm abweichende Verfassungsrealität in den Reichsstädten vor den Maßnahmen Karls V. deutlicher, daß nämlich in der Realität die Zunftmitglieder den ihnen gebotenen Rahmen an Mitbestimmung und Mitteilhabe am Stadtregiment aus zeitlichen und finanziellen Gründen gar nicht ausfüllen konnten, so daß der obrigkeitliche Trend im Regiment der Reichsstädte schon ins Spätmittelalter zurückreicht.

Die Verfassungswirklichkeit der Reichsstädte von der Mitte des 16. Jahrhunderts bis zum Ende des deutschen Reiches ist geprägt von einer Oligarchisierung der ratstragenden Schichten, von einer Schuldenwirtschaft der Reichsstädte, auf deren Ursache noch einzugehen sein wird, und von einem zunehmenden Modernitätsrückstand der reichsstädtischen Verwaltung gegenüber der der Territorien ${ }^{16}$, sowie von zahlreichen „Bürgerrevolten“, die namentlich in den letzten Jahren (Hildebrandt, Czok, Gerteis) ${ }^{17}$ unterschiedlich interpretiert wurden.

Das deutsche Reich nach dem Westfälischen Frieden war von der Tendenz bestimmt, Konflikte auf rechtlichem Wege zu lösen; dies führte dazu, daß von der gegen den Rat opponierenden Bürgerschaft immer häufiger die Reichsgerichte, das Reichskammergericht und der Reichshofrat, angerufen wurden ${ }^{18}$. Nachdem es Kaiser Leopold, gelungen war, das mit dem Westfälischen Frieden auf einen Tiefpunkt

\footnotetext{
${ }^{13}$ E. Naujoks (Hg.), Kaiser Karl V. und die Zunftverfassung. Ausgewahlte Aktenstücke zu den Verfassungsänderungen in den oberdeutschen Reichsstädten (1547-1556) (VKomLk in Baden-Wurttemberg A 36), Stuttgart 1985, S 1-25.

$14 \mathrm{~J} . J$. Moser, Von der Reichsstadtıschen Regiments-Verfassung. Frankfurt Leıpzig 1772

${ }^{15}$ Laurs, wie Anm. 12. S. 31-41.

${ }^{16}$ Gerteis, wie Anm. 5, S. 2.

${ }^{17}$ R. Hildebrandt, Rat contra Burgerschaft. Die Verfassungskonflikte in den Reichsstadten des 17 und 18. Jahrhunderts, in: Die alte Stadt 1 (1974). S. 221-241. K. C7ok. Zu den stadtischen Volksbewcgungen in den deutschen Territorialstaaten vom 16 bis zum 18 Jahrhundert. in W. RALSCH (Hg). wie Anm. 6, S. 21-42: K. Gerte.lS. Frühneuzeıtlıche Stadtrevolten ım sozıalen und instıtutıonellen Bedingungsrahmen. in: dito, S. 43-58.

${ }^{18}$ Bader, wie Anm. 2, S. 68. J.F. Noll. Der Reichshofrat und das Verfassungsleben der Reichsstadtc zur Zeit Josephs II., in: Esslinger Studien 16 (1970). S 121-131, H J Hecker. Die Reichsstadte und die obersten Reichsgerichte, in Katalog der Ausstellung ..Reichsstadte in Franken“. Munchen 1987. S. $169-182$.
} 
gesunkene Ansehen des Kaisers im Reich zu Ende des 17. Jahrhunderts wieder zu heben und namentlich die kleinen Stände Südwestdeutschlands auf Wien hin zu orientieren, gewann der Reichshofrat gegenüber dem Reichskammergericht das Übergewicht ${ }^{19}$.

Was die landsässigen Städte Südwestdeutschlands anbetrifft, so ist die Zeit zwischen der Mitte des 16. und dem Ende des 18. Jahrhunderts die Periode ihrer endgültigen Eingliederung in den Territorialstaat ${ }^{20}$. Bis zum Beginn des 16. Jahrhunderts war die landesfürstliche Verwaltung gegenüber den Territorialstädten eine intermittierende, die Konfliktfälle $\mathrm{zu}$ entschärfen und zu regeln hatte. $\mathrm{Zu}$ Ende der Periode sind die Magistrate landsässiger Städte zu staatlichen Behörden unterster Instanz geworden - wobei allerdings in einzelnen Territorien Unterschiede festzustellen sind. Erfolgten im 16. Jahrhundert Eingriffe des Landesherrn noch im Rahmen der Stadtrechte, wobei einzelne Aspekte aufgrund konkreter Anlässe in landesherrlichem Sinn interpretiert, schrittweise Wahlen beeinflußt und Kompetenzen der städtischen Behörden beschnitten wurden, so stand am Ende, in der Mitte des 18. Jahrhunderts, die Schaffung landeseinheitlicher Stadtverfassungen, die „Communordnung“ Johann Jakob Mosers in Württemberg von 1758, und die theresianische Stadtverfassungsreform zwischen 1752 und 1760 in den vorderösterreichischen Herrschaften, dort noch übertroffen von der Josephinischen Magistratsverfassung von 1785 .

Es ist guter historischer Stil, den schlechten Stand stadtgeschichtlicher Forschung für die Zeit zwischen 1550 und $1800 \mathrm{zu}$ beklagen ${ }^{21}$. Dies gilt für die Reichsstädte, vor allem aber und in viel stärkerem Maße für die landsässigen Städte. Den stadtgeschichtlichen Arbeitskreisen in Münster, in Esslingen und dem Südwestdeutschen Arbeitskreis für Stadtgeschichtsforschung ist es zu danken, daß sich die Kenntnis reichsstädtischer Verfassungs- und Verwaltungszustände seit 1550 in den letzten 30 Jahren wesentlich gebessert hat ${ }^{22}$. Was aber landsässige Städte angeht, steht man fast noch am Anfang. So schreibt Jürgen Sydow in seiner Monographie „Städte im deutschen Südwesten“: „Während festzustellen ist, daß die Erforschung der Kirchengeschichte für eine vergleichende Betrachtung der Städtegeschichte in der früheren Neuzeit recht viele Ergebnisse erarbeitet hat, ist auf anderen Gebieten bei weitem noch nicht so viel getan worden. Das betrifft die Verfassungsgeschichte ebenso wie die Wirtschafts- und Sozialgeschichte“ ${ }^{23}$.

Die mentalitätsgeschichtlichen Gründe für dieses Forschungsdefizit sind immer wieder aufgezeigt worden, zuletzt von Klaus Schreiner: „Anders als die mittelalterlichen Städte gab die Commune des 16. bis 18. Jahrhundert dem historisch-politischen Bewußtsein des 19. und frühen 20. Jahrhunderts keine Möglichkeit, als Faktor

\footnotetext{
${ }^{19} \mathrm{~V}$. Press, Die Erblande und das Reich von Albrecht II. bis Karl VI. (1438-1740), in: R A. KANN, FE Prinz (Hgg.), Deutschland und Österreich, Wien/München 1980, S. 44-88, hier S. 78-81. Vgl. auch NOEL, wie Anm. 10, S. 121-131.

${ }^{20} \mathrm{Vgl}$. allgemein dazu O. BRUNNER, Städtische Selbstregierung und neuzeitlicher Verwaltungsstaat in Österreıch, in: Österreichische Zeitschrift für öffentliches Recht NF 6 (1955), S. 221-249.

2'Sybow, wie Anm. 9, S. 187.

$22 \mathrm{Vgl}$. die für die damalige Forschungssituation programmatischen Aufsätze von $\mathrm{O}$. Borst, Die Kulturbedeutung der oberdeutschen Reichsstadt am Ende des alten Reiches, in: BlIDtLG 100 (1964). S. 159-246; DERS., wie Anm. 10, S. 106-194, und K.S. BADER, Über Sinn und Zıel reıchsstädtıscher Geschichte, in: Esslinger Studien 1 (1956), S. 9-14.

${ }^{23}$ Syoow, wie Anm. 9, S. 187.
} 
bürgerlicher Identitätsbildung zu wirken. Weder das bürgerliche Verfassungsdenken noch der Fortschrittsglaube des Liberalismus noch Genossenschaftsbewegungen des 19. Jahrhunderts konnten in der Stadt der Neuzeit Identifikationsmuster finden" 24. Deutlich spricht dies aus den Formulierungen der Darstellung Karl Biedermanns aus der Mitte des 19. Jahrhunderts: „Die Reichsstadt noch des 16. Jahrhunderts war der Ort, an dem sich der 'deutsche Freiheitssinn' hatte regen können."Die Herrschaft, die weltliche und geistliche Größe in ihren Mauern übten, hatten sie durch offene Gewalt gebrochen oder mit Geld abgekauft und waren damit "die stärksten Säulen deutscher Macht, die fruchtbarsten Pflanzstätten deutschen Handels und Gewerbefleißes, deutscher Kunst und Wissenschaft, geworden ${ }^{25}$. Indem sie sich dem Übermut der Landesherren entgegensetzten, den die kaiserliche Gewalt nicht mehr zu steuern vermochte, hatten sie, zu gleicher Zeit durch ihre alleinige Kraft dem deutschen Handel und dem Ansehen des deutschen Namens im Auslande weitere Bahnen gebrochen, als je ein Kaiser oder Fürstenmacht getan“. Diese verklärende Perspektive des 16. Jahrhunderts setzte bereits die reichsstädtische Publizistik des 18. Jahrhunderts der eigenen Gegenwart als Ideal gegenüber. Im Zustand des 16. Jahrhunderts sah man jenen "Gemein-Geist" verkörpert, der sich der "salus publica“ verpflichtet wußte, mit „warmer Vaterlandsliebe" und mit „keinerlei Herrschsucht” die Nähe zur Bürgerschaft aufrecht erhielt ${ }^{26}$. Im 18. Jahrhundert dagegen bevölkerte sie nur noch ein „verknöchertes, aufgeblasenes, saft- und kraftloses Spießbürgertum“ 27 . Die regierenden Magistrate hatten sich des städtischen Vermögens und der städtischen Rechte bemächtigt, die Justizpflege war in übler Verfassung, „Bedrückung und Aussaugung der Bürger die Regel“ ${ }^{28}$. Die kritischen zeitgenössischen Stimmen zur archaisierten Verfassungsgestalt und zur hypertrophen Funktionsweise der Reichsstädte ließen sich leicht vermehren und durch literarische Belege etwa bei Christoph Martin Wieland, der die Spätzeit Biberachs selbst als kommunaler Beamter erlebt hatte, oder bei Jean Paul, der der deutschen Reichsstadt im Roman des Armenadvokaten Siebenkäs ein satirisches Denkmal setzte, illustrieren. Erst jüngst konnte Roland Schurig aber dartun, daß sich aus der reichsstädtischen Historiographie des 18. Jahrhunderts eine zwar zu Teilen kritische, sonst aber durchaus positive Einstellung zu den eigenen Kommunen ablesen läßt ${ }^{29}$. Verteidigung der Gerechtsame der Städte nach außen wie auch eine Aktivierung der Bürger zur Stärkung des Gemeinwesens waren manifeste Ziele reichsstädtischer Historiographie ${ }^{30}$. Emotionaler Bezug zur unmittelbaren

\footnotetext{
${ }^{24} \mathrm{~K}$. SCHREINER, „Kommunebewegung“ und „Zunftrevolution“. Zur Gegenwart der mittelalterlichen Stadt im historisch-politischen Denken des 19 Jahrhunderts, in. F QUarthal W. Setzler (Hgg.). Stadtverfassung, Verfassungsstaat, Pressewesen. FS Eberhard Naujoks, Sigmaringen 1980, S. 139-168. DERS. Die Stadt des Mittelalters als Faktor bürgerlıcher Identıtatsbıldung. Zur Gegenwartıgkeıt des mittelalterlichen Stadtbürgertums im hıstonsch-polıtıschen Bewußtseın des 18., 19 und begınnenden 20. Jahrhunderts, in: Stadt im Wandel Landesausstellung Niedersachsen, Bd 4. Braunschweig 1985. S. $517-541$.

${ }^{25}$ BiedermanN, wie Anm. 1, S. 161

${ }^{26}$ Vgl. V. PFEIFER, Die Geschichtsschresbung der Reichsstadt Ulm von der Reformation bis zum Untergang des Alten Reiches (FGUlm 17), Ulm 1981, S. 142.

27 BiedermanN, wie Anm. 1. S. 161.

${ }^{28}$ Ebd.

${ }^{29} \mathrm{R}$. SCHURIG, Die reichsstädusche Geschichtsschreıbung im deutschen Südwesten am Ausgang des Alten Reiches, phil. Diss. (masch. u. Mikrofiches), Stuttgart 1989

${ }^{30}$ Ebd., S. 251.
} 
Umgebung wie ein Gemeinschaftsgefühl aller Reichsstädte waren die Motivation der literarischen und historiographischen Bemühungen um das „Vaterland“" 3 .

Das negative Urteil der Zeitgenossen hat die Forschung teilweise auch unbewußt tradiert, wobei es noch neuere Darstellungen bestimmt ${ }^{32}$. Noch 1983 schrieb Walther Hubatsch : „An die Stelle der selbstbewußten Städtebünde von einst war die trümmerhafte, schwäbische und rheinische Städtebank der Reichstage im 18. Jahrhundert getreten, mit gewiß gemütvollen, jedoch unbedeutenden Zügen eines Stillebens, das nichts mehr von lebenskräftigen Impulsen verspüren lie $B^{* 33}$. Man hat den Reichsstädten nach 1550 vorgeworfen, sich in ihrer Führungsschicht durch lebenslange Amtsinhaberschaft und Scheinwahlformen oligarchisch abgeschlossen ${ }^{34}$, die Verwaltung aufgebläht, überteuert, durch Vetternwirtschaft korrumpiert zu haben ${ }^{35}$. Machtpolitisch war die Reichsstadt kein Faktor mehr und deswegen nur an ihrer eigenen Erhaltung interessiert. K.S. Bader nannte dies ein „negatives Reichsbewußtsein“" ${ }^{36}$. Die überteuerte Bürokratie der Städte war der der fürstlichen Territorien unterlegen und ruinierte mit ihrer Schuldenwirtschaft das Gemeinwesen ${ }^{37}$. All

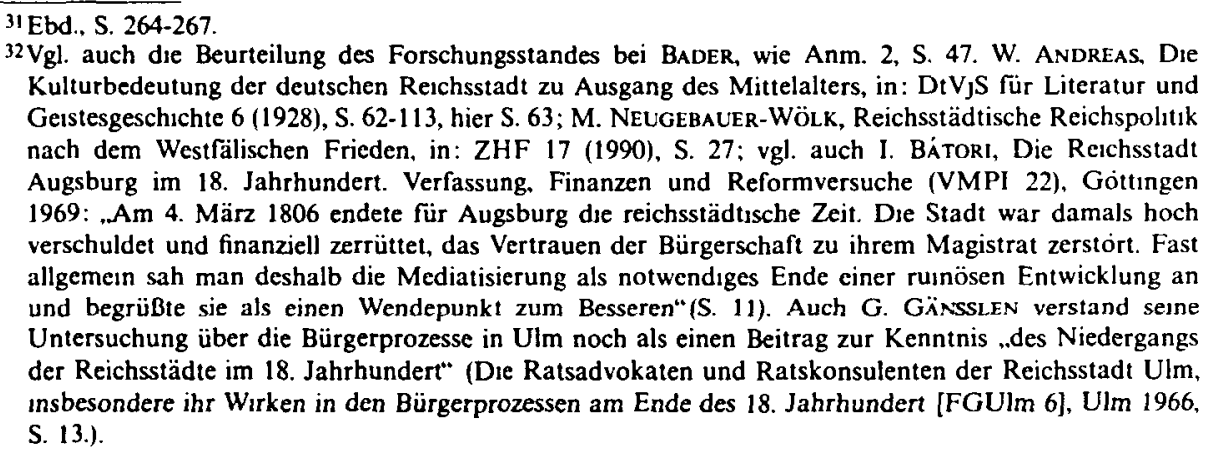

${ }^{33}$ W. Hubatsch, Ziele und Maßnahmen landesherrlicher Politik im Absolutusmus gegenüber Stadten aus der Sicht des Verwaltungshistorikers, in: Press (Hg.), wie Anm. 4, S. 30-44, hier S. 34.

${ }^{34}$ BADER, wie Anm. 4, S. 57; I. Bítori, wie Anm. 32, S. 54 u. 196. In Ulm wurde die Sublevationskommission und der Magistrat 1777 der Veruntreuung großer Geldsummen, schlechter Verwaltung, Parteilıchkeit, Bestechung und Bestechlichkeit, Nachlässigkeit, Bedrückung der Untertanen (der Burger) und Mißbrauchs der Schuldentılgung zum Nachteil der Bürger beschuldigt (GänssLen, wie Anm 32. S. 122).

${ }^{35}$ Gerade die Verklammerung von oligarchischer Herrschaftsausübung mit familiengebundenen Zugangsbeschrankungen galt in der liberalen Geschichtswissenschaft des 19. Jahrhunderts als ein besonders markantes Zeichen des maroden Verfassungssystems der frühneuzeitlichen Stadt. Vgl dagegen die Interpretation von Verwandtschaft als Kategorie des sozialen und rechtlichen Lebens der altständischen Gesellschaft bei K. SCHREINER, 'Consanguinitas'. 'Verwandtschaft' als Strukturprinzip relıgıöser Gemeinschafts- und Verfassungsbildung in Kirche und Mönchtum des Mittelalter, in: I. CRLSILS (Hg). Berträge zu Geschichte und Struktur der mittelalterlichen Germania Sacra, Göttingen 1989. S. 176-305. hicr S. 176-179. 274-305. Als Beispiel für zu enge Verwandtschaft im Rat vgl. GäNSSLEN, wie Anm. 32. S. $155-158$.

${ }^{36}$ Bader. wie Anm. 1, S. 58; DERS., wie Anm. 2. S. 68. Doch sah Bader auch positivere Zuge vgl di Rs., wie Anm. 10, S. 32.

${ }^{37} \mathrm{Vgl}$. auch für Nürnberg: F. BuHL, Der Niedergang der reichsstädtischen Finanzwissenschaft und die kasserlıche Subdelegats-Kommission von 1797-1806, in: MVGNürnberg 26 (1926), S. 110-228, H GeHring, Buchau am Federsee, Leutkirch und Wangen im Allgäu am Ende des alten Reiches Eın Beıtrag zur Stadigeschıchte dreter schwäbıscher Reichsstädte, phil. Diss. (masch.), Tubıngen 1954. GERTEIS, wse Anm. 5. S 91-93. Eındrucksvolle Beispiele wirtschaftlich durchaus gesunder Städte führte berests Borst wie Anm. 10, S. 108, an. Vgl. auch H. SPETH. Die Reichsstadt Isny am Ende des Alten Reiches 1775 1806. Untersuchungen uber Verfassungs-. Finanz-. Wirtschafts-und Sozalgeschichte der 
dies wurde interpretiert als die Folge einer mangelnden Kontrolle der Reichsstädte durch außenstehende Instanzen ${ }^{38}$.

$\mathrm{Da} B$ die Periode zwischen dem 16. und 18. Jahrhundert auch bei landesherrlichen Städten nicht zu den Glanzzeiten dieser Gemeinwesen gehört, ist ein Gemeinplatz auch landesgeschichtlicher Forschung ${ }^{39}$. Auch dort kam es zu Unruhen unter der Bürgerschaft, Aufruhr gegen den Rat, Beschwerden über finanzielle Mißwirtschaft ${ }^{40}$. Da Reichsstädte wie landsässige Städte aus vergleichbaren mittelalterlichen Rechtstraditionen herausgewachsen waren mit prinzipiell gleichem Streben nach rechtlicher wie wirtschaftlicher Autonomie, so hatten sich dort, trotz der Einbindung in ein landesherrliches Territorium, prinzipiell ähnliche Probleme ergeben. Zwar war überall im Laufe des Spätmittelalters der alte Rat durch einen Bürgerausschuß unter unterschiedlichsten Bezeichnungen (Rat, äußerer Rat, Zwölfer, usw.) erweitert worden, aber auch in den landsässigen Städten hatte sich diese neue Schicht als Obrigkeit von der übrigen Bürgerschaft abgeschlossen. Unzufriedenheit über die personelle und wirtschaftliche Praxis der Stadtverwaltung war in den landsässigen Städten Südwestdeutschlands ebenso verbreitet wie in den Reichsstädten. Nepotismus, lässige Amtsführung, Korruption und Veruntreuung öffentlicher Gelder wurden nicht weniger als in den Reichsstädten moniert ${ }^{41}$. Verschuldung und finanzielle Mißwirtschaft waren Dreh- und Angelpunkt der Kritik an der städtischen Verwaltung und den kommunalen Verfassungszuständen.

Seit Johann Jakob Mosers Feststellung, daß ,eine Reichsstadt ohne Schulden ein seltenes Exempel" sei, ist dies ein allgemeines Verdikt über die Qualität reichsstädtischer Verwaltung ${ }^{42}$. Für verschuldete Reichsstädte lassen sich in der Tat eine Fülle von Beispielen beibringen, die hier nicht im einzelnen wiederholt werden müssen ${ }^{43}$. Es wird jedoch übersehen, daß Verschuldung im 18. Jahrhundert nicht nur ein städtisches Problem war, sondern alle öffentlichen Bereiche betraf. Innerhalb des alten deutschen Reiches war jedoch so gut wie keine Institution zu finden, die nicht

Stadt im Vergleich mit Wangen 1. A. und Leutkırch (VKomLk in Baden-Wuirttemberg B 68), Stuttgart 1973 , S. $39-83$.

38 BADER, wie Anm. 1, S. 54-56.

${ }^{39}$ Rausch (Hg.), wie Anm. 6. S. 211

40 Belege lassen sich aus einzelnen Stadtgeschichten in großer Zahl beibringen. Eıne Zusammenstellung von Konfliktfällen in vorderöstereichischen Städten gibt E SEIDLER, Dıe vorderösterreıchıschen Landstädte im 18. Jahrhundert. Ihre Integratıon in den absolutıstıschen Staat unter besonderer Berucksichtigung der Reformen Marıa Theresıas und Josephs II., Wiss Arb. (masch), Tubıngen 1978. S 23-30.

41 Zum Phänomen der Korruption vgl. F. Quarthal, Korruption in Gesellschaft und Staat des Ancien Régıme, in: SozWissInf 16 (1987), S. 41-46; Zur Olıgarchisıerung der Stadiverwaltung in sachsischen Städten vgl. K. BLASchKe, Grundzuge der sächsischen Stadtgeschıchte im 17 und 18 Jahrhundert, In: Rausch (Hg.), wie Anm. 6, S. 173-180, hier S. 177. Unzufriedenheit und Kritık richteten sich allerdings nicht nur an die kommunalen Verwaltungen. Vor den Reformen der landesfürstlichen Verwaltungen um die Mitte des 18 Jahrhunderts werden auch diese wegen geringer Arbeitsmoral. Schlendrian, Vetternwirtschaft. Korruption, gerıngem Interesse fur die wirtschaftlıche Entwicklung und Überschuldung heftıgst kritısiert. Die Reformen setzten dort früher ein als in den Stadten. so daB der Modernitätsrückstand der Terntonen eher als ein temporäer als eın prinzıpıeller zu interpretıeren ist (Vgl. F. Quarthal, Absolutismus und Provinz. Verwaltungsreformen und Herrschaftsıntensıvierung in den österreichischen Vorlanden zur Zeit des Absolutismus, Tübingen [masch.]. 1982. S. 97-100)

$42 \mathrm{~J} . J$. Moser, Von der Reıchs-Stättıschen Regimentsverfassung. S 293, vgl. auch K K.S BAdr R. Johann Jakob Moser und die Stadte, in Esslınger Studien 4 (1958), S. 43-60

${ }^{43} \mathrm{Vgl}$. die Zusammenstellung be Borst, wie Anm 10, S. 148-153, und Hildebrandt. wie Anm 17. S. 230. 
verschuldet war $^{44}$. Von allen deutschen Territorien war dies nur Preußen zwischen 1718 und 1740 nicht. In der Regel mußten nach einer Untersuchung von Peter Claus Hartmann rund $50 \%$ des Haushaltes der deutschen Territorien des 18 . Jahrhunderts für Verwaltung und Schuldentilgung aufgebracht werden ${ }^{45}$. Die meisten der kleinen Landschaften im deutschen Südwesten haben ihren umfänglichsten archivalischen Niederschlag in den Akten der Schuldentilgungskommissionen der deutschen Mittelstaaten des 19. Jahrhunderts gefunden ${ }^{46}$. Die Verschuldung der Landstände war ein wesentliches Argument für deren Entmachtung und Unterstellung unter die Staatsaufsicht bei der Staatsreform Maria Theresias. Deren Finanzgebaren konnte nicht mehr der modernen, an kameralistischen Theorien ausgerichteten Konzeptionen einer Staatsadministration entsprechen ${ }^{47}$. Wenn man jedoch nur die Höhe der Schulden berücksichtigt, ohne deren Laufzeit, Zinssätze, Gläubigerkreise und Aufnahmegrund zu berücksichtigen, wird man immer zu falschen Interpretationen kommen. Schon im 18. Jahrhundert wurden Schulden häufig nicht im wirtschaftlichen Gesamtzusammenhang gesehen, sondern rein negativ als Ausdruck persönlichen Versagens und schlechter Verwaltungskunst interpretiert ${ }^{48}$. In der Tradition der Fürstenspiegelliteratur äußerte sich Johann Jakob Moser in seiner „Rechtlichen Betrachtung des Landes-Schulden-Wesens“ dazu: „Die Landes-Schulden haben mancherlei Ursprung. Insgesamt rühren sie von denen Schulden her, welche die Landes-Regenten gemacht hatten, und nicht bezahlen konnten, oder wollten; dahero dem Land angesonnen wurde, selbige ihnen ab und auf sich zu nehmen, zumalen wann es einen Regierungsnachfolger betraffe, welcher, weil er die Schulden nicht gemacht hatte, selbige auch nicht zahlen, und lieber aus fremdem, als eigenem, Leder Riemen schneiden wollte“ ${ }^{49}$. Schulden sind aber - im Gegensatz zu häufigen Darstellungen in historischen Untersuchungen - nichts eo ipso Negatives, solange die Kreditfähigkeit einer Institution erhalten bleibt. Sie verdichten jede Institution und perpetuieren sie stärker als jedes andere Vehikel. Schulden sind ein Movens des frühmodernen Staates. Bei Franz Stephan von Lothringen, dem Gemahl Maria Theresias, werden in neueren Darstellungen seine Fähigkeiten als Wirtschaftsfachmann hervorgehoben, nicht weil er die Schulden Österreichs beseitigt, sondern weil er ihre Dauerhaftigkeit und Abzahlbarkeit gesichert hatte ${ }^{50}$.

Ich meine also, daß die bisherige Trennung der Verfassungs- und Verwaltungsgeschichte der frühneuzeitlichen Territorien, ihrer landsässigen Städte und der Reichsstädte zu einer Verzeichnung der städtischen Verwaltung geführt hat. Die

44F. QUARTHAL, Öffentliche Armut, Akademikerschwemme und Massenarbettslosigkeit im Zeitalter des Barock, in: V. Press u.a. (Hgg.), Barock am Oberrheın (Oberrheinısche Studien 6), Karlsruhe 1985. S. 159-165.

45PC. HaRtmann, Geld als Instrument europäischer Machtpolitik tm Zeitalter des Merkantilismus. München 1978, S. 30.

46P BuICKLE. Landschaften im alten Reich. Die staatliche Funktion des gemeinen Mannes in Oberdeutschland, Munchen 1973, S. XIX.

${ }^{47}$ Quarthal, wie Anm. 5, S. 325f.

48 Vgl. schon M. von OSSE, Prudentia Regnatıva. Das ist Nutzlıches Bedencken, ein Regiment [. .] recht zu bestellen, Frankfurt a.M. 1607.

${ }^{49}$ Von den Teutschen Reichs-Stände Landen, deren Landständen. Unterthanen, Landes-Freyheiten, Beschwerden, Schulden und Zusammenkünften, Frankfurt und Leipzig 1769, S. 1377.

${ }^{5} \mathrm{H}$ L. Mikoletzky, Franz Stephan von Lothnngen als Finanz- und Wirtschaftsfachmann, in. Maria Theresia und thre Zeit. Zur 200. Wiederkehr ihres Todestages, Ausstellungskatalog. Wien 1980. S. 422428 
Probleme sind in allen drei Gebilden vergleichbar und haben zu Lösungsversuchen geführt, die nicht völlig unähnlich sind.

Kann sich eine Untersuchung reichsstädtischer Verwaltungs- und Wirtschaftsgeschichte in der Zwischenzeit auf eine stattliche Anzahl lokaler und zusammenfassender Abhandlungen stützen, so ist die Zahl der Vorarbeiten für landsässige Städte wesentlich geringer, da sie insgesamt nicht die gleichen Interessen wie die Reichsstände gefunden haben, was auch forschungsgeschichtliche Ursachen hat, waren die landsässigen Städte doch — zumindest in Südwestdeutschland - , ,nicht nur wirtschaftlich weniger bedeutend und politisch minder mächtig als die Reichsstädte, sondern sie entbehrten auch jenes Elements der Freiheit, das es erlaubt hätte, zeitnahe Probleme bei einer Auseinandersetzung mit ihnen wiederzufinden" 51 .

Eine vergleichende Untersuchung im südwestdeutschen Raum gibt es nur für Württemberg, wo Hans Eugen Specker eine Zusammenstellung der normativen Vorschriften für die Verwaltung landsässiger Städte unternommen hat ${ }^{52}$ - eine empirische Überprüfung am Einzelfall — wie sie im Rahmen dieser Tagung für Norddeutschland vorgelegt wurde - , steht noch aus ${ }^{53}$.

Im folgenden seien Entwicklungslinien von Verfassungsänderungen in vorderösterreichischen Landstädten als Beispiel für das Zusammenwirken städtischer Bewegung und landesfürstlichem Interesse an Integration und Zentralisation des Territoriums dargestellt. Bis zum 14. Jahrhundert war der landesherrliche Verwaltungsapparat - nicht nur in den habsburgischen Gebieten - noch so wenig ausgebildet, da $ß$ die Selbstverwaltung kleinerer Landeseinheiten - wie der Städte - unumgänglich war. Otto Brunner sprach für die Städte des Herzogtums Österreich davon, daß die Beziehungen zwischen Stadtherrn und Städten „außenpolitischen“ Charakter getragen hätten ${ }^{54}$. Der ,intermittierende Charakter" der mittelalterlichen Regierungsweise machte effektive Lokalverwaltungen unabdingbar - ein Aspekt, der in der südwestdeutschen Interpretation der Rechtsverhältnisse habsburgischer Städte häufig fälschlich als "quasi reichsstädtische Freiheit" interpretiert wurde. Seit dem 16. Jahrhundert mehrten sich aber die Versuche, die Landeshoheit auch in den Städten unmittelbar auszuüben. Es lassen sich dabei drei Etappen unterscheiden, in denen die direkten Eingriffe in städtische Verfassungs- und Verwaltungsangelegenheiten sukzessive zunahmen:

Im 15. Jahrhundert unterstützte die Regierung die Versuche des Rates der einzelnen Städte, das Wahlrecht auf einen engen Kreis zu beschränken, die Ratsspitze

5IF. QUaRTHaL, Die Verfassungsänderungen in den Städten Vorderösterreıchs im Rahmen der Staatsreformen Maria Theresias, in. Quarthal/Setzler (Hgg.), wie Anm. 24, S. 121-138, hier S 122 Fur landsässige Stadte in Österreıch vgl. BrunNer, wie Anm. 20, S. 221f.; allgemeın GerTfı, wie Anm 5 , S. $71-74$.

${ }^{52}$ H.E. SPECKER, Die Verfassung und Verwaltung der württembergischen Amtstädte im 17 und 18. Jahrhundert, dargestellt am Beispiel Sindelfingen. in. E. Mascrke/J SYdow (Hgg.). Verwaltung und Gesellschaft in der südwestdeutschen Stadt des 17. und 18. Jahrhunderts (VKomLk in Baden-Wurttemberg B 58), Stuttgart 1969, S. 1-21; für das spate Mittelalter vgl. R SEl(,EL, Die württembergische Stadt am Ausgang des Mittelalters. Probleme der Verfassungs- und Sozıalstruktur, in: W. Racsch (Hg.), Die Stadt am Ausgang des Mittelalters (Beitrage zur Geschıchte der Städte Mitteleuropas 3). Linz/Donau 1974, S. 177-200. Seıgel hat ebenfalls für das Mittelalter eine vergleichende Untersuchung zu innerschwäbıschen Landstadten vorgelegt ( $R$ SEıGEL. ..Innerschwabısche Landstädte“ Ein Beıtrag zur vergleichenden Verfassungsgeschichte, in: Konstanzer Arbeitskreis fur mittelalterliche Geschichte. Protokoll (masch.) der Sitzung vom 18.04 1961)

${ }^{53} \mathrm{Vgl}$. den Aufsatz von Christine van den Heuvel in diesem Band

54 BrunNer. Wie Anm. 20, S 231 
möglichst klein zu halten und obrigkeitlich auszugestalten. Je kleiner die Schicht politisch einfluBreicher Bürger war, desto eher vermochte die Regierung auf diese innerstädtischen Einfluß auszuüben. Zunächst beschränkten sich die Eingriffe der Regierung auf vereinzelte Maßnahmen.

Systematischeren Charakter hatten jedoch die relativ häufigen Einsetzungen von Wahlkommissaren seit dem 16. Jahrhundert. Die Überwachung der Ratswahlen wurde zugleich zu einer Überprüfung des städtischen Finanzwesens und damit des gesamten Aktionskreises des Rates benützt. In diesen systematischen landesherrlichen Eingriffen sah Brunner den wesentlichen Übergang im Charakter der landesherrlichen Verwaltung von einer intermittierenden zur kontinuierlichen Verwaltungshandlung ${ }^{55}$. Nach den Wahlen gerieten Rechtssprechung, Militär und Steuerverwaltung unter landesherrliche Oberaufsicht. Aus der Kontrolle des Wahlvorgangs in landesherrlichen Städten bei der Neuwahl des Rates wurden immer ausführlichere Anweisungen und Instruktionen für die städtische Verwaltung insgesamt ${ }^{56}$.

Im Laufe des 18. Jahrhunderts weitete sich die landesherrliche Einfiußnahme aus. Nunmehr geriet auch der autonome, genossenschaftliche Bereich des städtischen Lebens in das Blickfeld kontinuierlichen landesherrlichen Verwaltungshandelns. Dabei wurden die Eingriffe der Regierung teilweise durch innerstädtische Spannungen hervorgerufen, teilweise führten die Maßnahmen der Regierung selbst zu Unruhen in den Städten. Wegen der vielschichtigen Territorialstruktur der österreichischen Vorlande verlief diese Entwicklung nicht in einer klaren und deutlichen Linie ${ }^{57}$. Brüche gab es in der landesherrlichen Zuständigkeit - manche Maßnahmen wurden durch die Regierung in Innsbruck, andere durch die vorderösterreichische Regierung und Kammer in Ensisheim, später in Freiburg, eingeleitet, manche Anordnungen nach 1665 von Wien aus widerrufen. Auf einige Städte hatte der Landesherr unmittelbaren Zugriff, andere, wie etwa die Donaustädte Munderkingen, Riedlingen, Saulgau, Mengen und Waldsee, standen unter einer Pfandherrschaft, die eigene Rechte in den Pfandstädten beanspruchte. Ein geschlossenes Konzept zu einer gesamten Reform der Stadtverfassungen konnte es daher erst im Rahmen der alle Bereiche umfassenden Staatsreform Maria Theresias kommen, wobei auch dann noch Rücksicht auf lokale Besonderheiten genommen wurde.

Die vorländischen Städte der Habsburger entstammten keiner einheitlichen Stadtrechtsfamilie, nur in Laufenburg, Waldshut, Säckingen, Aach und Mengen waren Gründungen der Habsburger selbst. Andere, die durch Kauf an Österreich kamen, waren geistliche Gründungen (Radolfzell, Breisach) oder von anderen Adelsfamilien gegründet, von den Zähringern, den Üsenbergern, den Grafen von Zollern, von Hohenberg, den Herzögen von Teck, den Herren von Waldsee und den Grafen von Berg. Breisach und Neuenburg wurden den Habsburgern vom Reich verpfändet, Willingen und Freiburg unterstellten sich ihnen freiwillig ${ }^{58}$.

In Freiburg griff Erzherzog Albrecht 1454 unmittelbar in die Stadtverfassung ein; dies war insofern eine besondere Situation, die sich von anderen vorderösterreichi-

\footnotetext{
s5Ebd., S. 237.

${ }^{56}$ Ein vorzügliches Betspiel, wie intensıv die landesfürstlichen Behörden schon zu Anfang des 17. Jahrhunderts trotz großer Entfernung in alle Bereıche städtıschen Lebens eingrifien, bieten die Maßnahmen der Innsbrucker Regierung in Rottenburg (vgl. K. KEMPF, Die Chronik des Christoph Lutz von Lutzenhartt aus Rottenburg am Neckar, Vashingen/Enz 1986, S. 305-353).

${ }^{57}$ Ich beschranke mich auf die Städte, die nach 1648 habsburgisch blieben.

${ }^{5 x} \mathrm{Vgl}$. Historischer Atlas von Baden-Würtemberg. Beiwort zur Karte VI, 4.
} 
schen Städten unterschied, da Freiburg unter ihm vorländische Residenzstadt war ${ }^{59}$. Nach dem Rückzug der Geschlechter aus der Stadtherrschaft kam es in Freiburg zu einem Zunftregiment, das sich gegen Ende des 15. Jahrhunderts oligarchisch abschloB. Im 16. Jahrhundert bemühten sich die führenden Familien darum, einen beständigen Rat aus zwölf lebenslänglich gewählten Mitgliedern zu bilden und holten sich dafür die Zustimmung der vorderösterreichischen Regierung in Ensisheim. die dieses Ratsregiment, das ihr größere Einflußmöglichkeiten eröffnete, 1557 genehmigte. Seitdem durfte kein Ratsmitglied mehr ohne ausdrückliche Genehmigung der Regierung aufgenommen werden, insbesondere die Zunftmeister waren einer Regierungskommission vorzustellen, die die Wahlen beaufsichtigte. Der beständige Rat sollte alle wichtigen Angelegenheiten beraten, ohne die Zunftmeister hinzuzuzichen. War der Landvogt anwesend, hatte er an Stelle des Bürgermeisters die Umfrage zu leiten. Gegen diese Bevormundung widersetzten sich die Bürger erfolglos, die Regierung antwortete in einem Ton, der keinen Zweifel mehr zuließ, wer letztlich als Obrigkeit zu verstehen war: ..Ihr werdet Euch unterwerfen und uns nicht Ursache geben, daß wir etwa der Zünfte halber eine Änderung vornehmen*. Als die vorderösterreichische Regierung nach 1648 ihren Sitz in Freiburg nahm, geriet der Rat zunehmend unter landesherrlichen EinfluB. Nach 1666 wurde immer deutlicher, daß die Regierung den städtischen Rat als ein ausführendes landesherrliches Organ betrachtete, der Rat sich aber noch als städtische Obrigkeit verstand. Nachdem Freiburg 1698 wieder an Österreich gekommen war, setzte die Regierung dem Rat einen „Oberschultheiß“ als ständigen landesherrlichen Kommissar vor, der die Tätigkeit des Rates voll kontrollierte. In der ersten Hälfte des 18. Jahrhunderts überwachte eine Regierungskommission die Wahlen; als Festung waren weite Bereiche städtischen Handelns dem Stadtrat entzogen ${ }^{60}$.

Die Stadt Neuenburg hatte zunächst eine stark zünftisch bestimmte Stadtverfassung. Sie verfügte über das Schultheißenamt, die hohe und niedere Gerichtsbarkeit. Das relativ ,aristokratische“" Ratsregiment, das namentlich bei Wahlen die Gemeinde nahezu ausschloB, verursachte Unmut in der Bürgerschaft: Der abtretende Rat bestimmte jeweils vier „neue Räte“ aus seinem Kreis, die die Kontinuität der Regierung wahren sollten. Diese kooptierten vier weitere Mitglieder, dieses Gremium nochmals vier, bis 16 Räte vollzählig waren. Die Gemeinde wartete während des Wahlvorgangs vor dem Rathaus und hatte bei jedem Wahlgang zu akklamieren. Wegen der abnehmenden Bürgerzahl war die Zahl der Räte in der ersten Hälfte des 18. Jahrhunderts auf acht reduziert worden. Seit dem 16. Jahrhundert überwachte eine Kommission der vorderösterreichischen Regierung die Wahl, wobei auch hier meist die Stadtrechnungen kontrolliert wurden. Nach 1671 weitete die Wahlkommission ihre Eingrife in städtische Belange aus, 1674 führten finanzielle Mißstände zu direkten Aktionen. Auch hier wurde im 18. Jahrhundert durch landesherrliche Maßnahmen die städtische Autonomie faktisch beiseite geschoben: Nach Bürgerunruhen wurde 1739 der Magistrat abgesetzt und durch einen neuen ersetzt.

An der Entwicklung in Breisach lassen sich relevante Unterschiede zwischen Reichsstadt und landsässiger Stadt sichtbar machen. Wie in den bisher behandelten Städten hatte der Rat den Charakter einer Vertretung der Bürgerschaft verloren

\footnotetext{
${ }^{59}$ BRUNNER, wie Anm. 20, S 241.

6OSEJDLER, wie Anm 40, S 32-36.
} 
und war zur Obrigkeit geworden ${ }^{61}$. Zu bürgerschaftlichen Unruhen kam es jedoch erst, als sich die ökonomische Situation der Stadt zwischen 1720 und 1740 drastisch verschlechtert hatte und dem oligarchischen Rat nunmehr der Vorwurf von Mißwirtschaft und finanziellem Fehlverhalten gemacht wurde ${ }^{62}$. Die Beschwerden der Bürgerschaft zielten auf drei Aspekte: den der Stadtverfassung, der Verwaltung sowie der schlechten Rechtsadministration und Korruption. Nunmehr wurde der Ausschluß der Bürgerschaft von der Bürgermeisterwahl und das auf bestimmte Zunftzugehörigkeit und Verwandtschaftskreis eingeschränkte passive Wahlrecht zum Rat moniert. Unkontrollierte Wirtschaftsführung, überhöhte Personalanstellung und Besoldung sowie widerrechtliche Besteuerung waren Monita, die die Verwaltung betrafen. Dem Bürgermeister wurde eine Verletzung der Rechtsförmlichkeit in der Rechtsprechung und die Ausschaltung des Rats aus der Gerichtsbarkeit vorgeworfen. In der Klageschrift der Breisacher Bürger wird deutlich, daß sie den Rat als bedrückende Obrigkeit, die österreichische Herrschaft dagegen als Freiheitsgarantie gegen die Übergriffe des Magistrats empfanden. Während der Magistrat das Eingreifen der Regierung als Freiheitsbeschränkung auffaßte, bedauerten die Bürger, da B sie als „freie österreichische Bürgerschaft [...] im mindesten nicht die süße Landesregierung und österreichische Gelindigkeit ihrer königlichen allergnädigsten Landesmutter [...] empfinden“, welche sie gegen ihrer ,näheren Obrigkeit Joch“ beschützen solle. Während den Reichsstädten bei Mißständen nur der Weg des Aufruhrs oder der externen Anrufung der Reichsgerichte offenstand, konnten die landsässigen Städte je länger je mehr den ausgebildeten Instanzenzug des Territoriums nützen. Je mehr sich die landesherrliche Verwaltung ausdifferenzierte, umso mehr verloren landesherrliche Eingriffe den außergewöhnlichen Charakter und wurden zu kontinuierlichem Verwaltungshandeln.

Gegenwärtig ist es noch nicht möglich, eine Typologie der habsburgischen Städte in den Vorlanden nach der Form der Ratsverfassung, der Art der Beteiligung der Zünfte und Geschlechter, der Leitung der Städte durch Bürgermeister oder Schultheißen oder dem $\mathrm{MaB}$ der herrschaftlichen Mitbestimmung an der Führung der Stadtgeschäfte zu erstellen. Selbst der Charakter als - mit der Diktion des 18. Jahrhunderts - Kameralstadt oder verpfändeter Stadt wechselte, so daß jeweils mehrere zeitliche Querschnitte erforderlich sind, um ein korrektes Bild der jeweiligen historischen Situation zu zeichnen.

Ursprünglich standen alle Städte als herrschaftliche Gründungen unter einem Beamten des Stadtherrn, dem Stadtamman oder Schultheißen, der die Oberaufsicht über das Gerichtswesen innehatte und Verwaltung, Wirtschaft und Polizei der Städte kontrollierte. Angesichts der differenzierten Genese dieser 30 Städte, der unterschiedlichen Stadtgründer sowie ihrer breiten geographischen Streuung dieser Städte ist evident, da $B$ deren mittelalterliche Verfassungen ein sehr divergentes Bild boten. Wie andere Territorialherren vereinheitlichten die Habsburger diese Stadtrechte nicht, sondern bestätigten in ihrem Namen gewachsene Rechtsstrukturen. Sie schufen auch keine einheitlichen Verwaltungsbezirke - etwa in der Form von Stadt und Amt wie in Württemberg -, sondern beließen in der Regel die Stadt und ihr Umland in zwei

6'G HASElier. Geschichte der Stadt Breisach am Rhein, Bd. 1. Breısach 1977, S. 55f.

62 Beschwerdeschrift der Breisacher Burger an Regierung und Kammer in Freiburg vom 19. Dezember 1742 (HASELIER, wie Anm 61, S 57-60) 
Mengen Gf v Veringen (") I276 Stadtrechesvertecthung Rudolf Gf $v$ Vering

Kg Adolf kaufte 1298 castellum K mtt Stadt Usenberger a Lehen

Grundung

Riedlingen Gf Wolfrad v Verigen um 1250

Kerren $x$ Tmerkingen Statir

Saulgau

Kaluer Fredrich II IIIs:36, Stad

Burgau Sedlungsherrn G, fn * Berg, Stadtgrundurg unbekannt

Gunztury Gi Albrecht I (1298-1308)

Stadtgrunder Herren $\vee$ Aach, Studtrechic $1287 \mathrm{Ks}$ F riedrich 111

vor $1297 \mathrm{Kaur}$

1299 Kauf

Mit Ubergang der Markgrafuhdaft Burgau 130 Grundung

\section{Radolfzell Marktrecht 1100. Stadtrecht 1267.}

Stadtherr Abt $v$ Reschenau

Cirundung 117 V Tahringen, Stadtrechtsverleihun

Breisatch 1185 Stadigrundung, gem Verwaliung Heinnech II

Neuenburg Stadtgrundung 117080 durch Berthold IV 、 Zahringen

Waldwee Girunder u Stadiheren Hierren * Waldsee Stadtrecht 1298

Stadterundung vor 1253 durch 6 fin $v$ Berg

Villingen 1119 durch $\mathrm{Hz}$ 、 Zahringer

Rheinielden 1125 durch Konrad $\vee 7$ ahringen

Triberg Stadigrunder Gf $\checkmark$ Hohenberg ind Habshurg.

Indingen Stadigrundung um 128586 durch Heaso * Usenterg

I retbusg um 1220) Marktgrundung Jurch Konrud v 7ahringen (")

Burkheim Sidatgrunder Herren v Usenberg, ca 1300

Rottenburg 1280 Stadtgrundung Jurch Ge Altert 11 * Hohenberg

1300 Kauf

I298 Kauf

1305

Aneignung 1275, 1330 an Habsburg verpfandet

Nach Anfall an Rech 1331 an Hz Albrecht U Otto v Outerrech versety

1343 mit Herruthuft Berg gekaufi

1343 mit Herrshaft Berg gekauft

1326 Stadt stellte sich unter Sehut/ Albrechts $\checkmark$ Jlabsburg

nach Anfall an Reich 1330 an Habsburg verpfandet
$1355 \mathrm{~K}$ duf

1564

13841680 an Haus Waldburg

1384 an Haus Waldburg 1384 an Haus Waldburg

$16 \times 0$ Selbstauslosung 1386 an thaus Waldhurg

680 Selbstauslosung 1680 Selbstauslosung

1458 86 an Bischof y Augsburg 155

1330 Verplindung an Truchsess

13001325 an Herren

* Klingenberg

im 1 125. jedenfalls

vor 1462

146974 an Burgund

1568 an Stadt

135275 an Hohenbers

1386 Waldburg

sert 1360 an uniersch Herren

seet 1680 an Schenk-Castell

$16 \$ 0$ Selthrauslosung

1568 Selbatauslosung

\section{Ubergang an Habsburg}

Nach Loskauf $\vee$ (if $\vee$ Urach unter habsburgisehem Schutz 1368

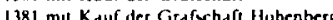


unterschiedlichen Rechtsbezirken. Wenn sich die Stadt einen eigenen Gerichtsbezirk im ländlichen Umfeld schuf, geschah dies zumeist über den städtischen Spital. Die meisten der habsburgischen Städte in Südwestdeutschland kamen nach kurzer Zeit als „Mediatstädte“ (so die Bezeichnung im 18. Jahrhundert) wieder unter einen Pfandherren. Da die Habsburger ihre Immediatstädte wic dic Pfandherren die Mediatstädte in unterschiedlichem Maße privilegierten, wurde die Verfassungsentwicklung der österreichischen Städte in Südwestdeutschland zwischen dem 15. und 17. Jahrhundert eher uneinheitlicher als homogen.

Ein Versuch, Entwicklungslinien vom späten Mittelalter zur frühen Neuzeit hin aufzuzeigen, mag deswegen problematisch sein. Als Maßstab kann die Entwicklung der Selbstverwaltung mit den Institutionen von Gericht und Rat dienen ${ }^{64}$. Im Laufe des 14. Jahrhunderts gelang den meisten habsburgischen Städten die Ausweitung ihrer Gerechtsame in zwei Richtungen: Sie konnten - mit Ausnahme von Binsdorf, Obernau, Tengen und Burgau - eigene Gerichtsbezirke bilden. Dazu wurde das mit Bürgern besetzte Stadtgericht zur bestimmenden Gerichtsinstanz; dies war eine der wesentlichen Grundlagen städtischer Unabhängigkeit.

Als der Mehrzahl der Gerichte auch die hohe bzw. die Blutsgerichtsbarkeit verliehen wurde, vergrößerte sich der Kompetenzbereich des Ammans, der dem Gericht jeweils vorstand.

Die Auseinandersetzung um größere städtische Autonomie der südwestdeutschen Städte der Habsburger läßt sich danach in drei Phasen gliedern: erstens dem Versuch, das Wahl- oder Einsetzungsrecht für den Amman zu erlangen und ihn dadurch zu kommunalisieren, zweitens die Periode der Einrichtung eines bürgerlichen Ratsgremiums, das unter einem gewählten Bürgermeister neben das Gericht trat und drittens die Phase der Ablösung des Ammans durch den Bürgermeister, wobei ersterer auf den Gerichtsvorsitz beschränkt wurde.

Die frühneuzeitliche Stellung der habsburgischen landsässigen Städte bestimmte sich jedoch nur teilweise aus ihrer im Spätmittelalter durch Stadtrecht und Privilegierung, Territorialbesitz und Gerichtsrechte erworbenen Stellung. Stärker war die Abhängigkeit von unmittelbaren herrschaftlichen Einwirkungsmöglichkeiten. Dabei lassen sich folgende Stufen feststellen:

1. Städte mit "quasi reichsstädtischer Freiheit".

Dies galt für wenige Städte während einer begrenzten Periode, wobei eine gute rechtliche Privilegierung, Territorialbesitz und Gerichtsrechte sowie die Auslösung aus Pfandbesitz vor der Institutionalisierung neuer Mittelbehörden im 18. Jahrhundert die Voraussetzung waren. In diese Gruppe gehören Ehingen und die fünf Donaustädte in der Zeit zwischen 1680 und der Oberamtsreform Kaiser Karls VI. nach 1726.

2. Städte mit herrschaftlichem Gerichtsvorsitz, aber teilweise unabhängiger Ratsverfassung (z.B. Rottenburg, Horb, Günzburg, Villingen)

3. Städte unter stark herrschaftlichem Regiment (Burgau, Binsdorf)

4. Städte in deutlicher Abhängigkeit von einer Pfandherrschaft (Triberg, Weißenhorn).

\footnotetext{
o4 Als modellhaft sind immer noch die Arbeiten von R. SEIGEL anzusehen (Gericht und Rat in Tubingen Von den Anfangen bis zur Einführung der Gemeindeverfassung 1818-1822 [VKomLk in BadenWurttemberg B 13]. Stuttgart 1960).
} 
Stadtrechtserneuerung gab es zwar während der ganzen Zeit des 16., 17. und frühen 18. Jahrhunderts, doch beschränkte sie sich jeweils auf Einzelfälle. Zu einer durchgehenden Kommunordnung ist es nicht gekommen; entsprechende Versuche der Innsbrucker Behörden nach 1726 sind in Ansätzen stecken geblieben.

Erst mit der theresianischen Staatsreform wurden 1753/56 alle landesherrlichen Eingriffe in das Städtewesen systematisiert ${ }^{65}$ und alle Stadtverfassungen nach einem einheitlichen Plan, wenn auch mit geringen lokalen Abweichungen, erneuert ${ }^{66}$.

Nach dieser Reform waren in allen österreichischen Städten der Vorlande ,neue Stattsverfassungen zu Einfuhr- und Unterhaltung besserer oekonomiae und Polizey einzurichten“. Der Rat war nunmehr dreigliedrig aufzubauen. Das wichtigste Gremium war die „Engere Deputation“, die aus den fähigsten Bürgern - ,jedoch ausschließlich der Zunfftmäßigen Handtwercksglieder" - bestehen sollte, nämlich einem Bürgermeister, dem Stadtamman und zwei Ratsmitgliedern neben einem rechtsgelehrten Kanzleiverwalter. Die Anstellung des Kanzleiverwalters als eines nunmehr landesfürstlichen Beamten behielt sich die vorderösterreichische Regierung vor. Keines der Mitglieder dieser „Engeren“ oder „Ökonomiedeputation“, die das „Universalaufsehen“ über die Stadtgeschäfte haben sollte, durfte ein verrechnetes Amt (Säckel-, Steuer-, Wald-, Bau-, Spitalamts- oder Mildestiftungspflegerei, Umgeld-, Fleisch- und Brotbeschauamt) innehaben.

Zusammen mit acht weiteren Räten bildete die Ökonomiedepuation als „Innerer Rat" die städtische Zivil- und Kriminalinstanz zur Entscheidung über bürgerliche Streitsachen. Der Innere Rat hatte alle vierzehn Tage zusammenzutreten.

Das dritte Gremium, die „bürgerliche Deputation“ oder der „Große (Äußere) Rat", bestand aus sechs Personen und dem Inneren Rat. Sie hatten zu befinden, wenn es um wichtige Stadtangelegenheiten wie Verpfändung, Verkauf von Stadtgütern oder Kapitalaufnahmen ging. Da diese Beschlüsse nur Gültigkeit hatten, wenn sie die Zustimmung des jeweiligen Oberamtes fanden, war die wirkliche Kompetenz des "Großen Rates" nur gering. Überdeutlich war nunmehr die obrigkeitliche Einbindung der kommunalen Entscheidungen in die landesherrliche Administration ${ }^{67}$.

Wichtig erscheint es mir jedoch, darauf hinzuweisen, da $B$ selbst in einem Großterritorium, wie es die habsburgischen Erblande darstellten, es nicht auf Anhieb gelang, die Reform durchzusetzen ${ }^{68}$. Auch das jahrhundertelang und ständig erweiterte und institutionalisierte Eingriffsrecht des Landesherrn in Belange der Verfas-

\footnotetext{
${ }^{65}$ Wichtig ist, daß diese Veränderung der Stadtverfassung nicht nur die Vorlande, sondern alle deutschen Erbländer betraf. Vgl. z.B. für Niederösterretch F. BALTZAREK, Beiträge zur Geschıchte des vierten Standes in Niederösterreich. Eine vergleıchende Stadtgeschichtsuntersuchung mıt besonderer Auswertung der Gaisruckschen Städteordnung von 1745-1747, in: MOStA 23 (1970). S. 64-104.

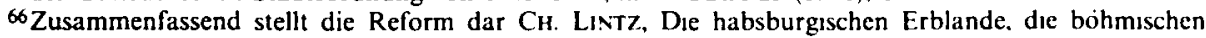
Länder und Salzburg, in: K.G A JeSERich u.a. (Hgg.), Deutsche Verwaltungsgeschichte, Bd 1. Stuttgart 1983, S. 516-543; zur Entwicklung in den Vorlanden vgl F. QLaRThal. Zur Geschichte der Verwaltung der österreichischen Vorlande, in: F. QLaRTHaL/G Wieland (Hgg.). Die Behordenorganisation Vorderösterreschs und die Beamten in Verwaltung. Justız und Unterichtswesen (VAlemaninst 43). Bühl/Baden 1977, S. 43-130; zu den Reformen in den Stadten QLARTHAL, wie Anm 51, S 121-138. SEIDLER, wie Anm. 40, S. 88-152. Entsprechend der früheren Einfuhrung der theresianıschen Reformen in den habsburgischen Kernlanden erfolgte die Reform der Stadtverwaltungen und die Unterstellungen der Städte unter dıe „stadtısche Wahlkommıssion“ der ..Niederösterreıchıschen Repräsentatıon und Kammer" bereits 1747 (BruNNer, wie Anm. 20. S. 245).

${ }^{67} \mathrm{Zu}$ den Einzelheiten vgl. die in Anm. 66 genannten Arbeiten.

${ }^{68}$ In Niederösterreıch führt OTro BRUNiNer (wie Anm. 20, S 246) die Stadte Krems und Stern als Beıspiele vor. $\mathrm{Zu}$ ähnlıchen Schwierıgkeıten in Preußen in der ersten Halfte des 18 Jahrhundert,
} 
sung der Landstädte wurde nicht ohne Widerspruch, teilweise sogar verbunden mit Aufständen, hingenommen.

Einige Beispiele mögen dies belegen: In Munderkingen, das ausgesprochen zünftisch bestimmt war, wurde die Instruktion glatt übergangen. Man änderte die Namen der Gremien, beließ jedoch inhaltlich alles beim alten. Erst als die Zunftmeister mit Zuchthaus und Bürgerrechtsentzug bestraft und ein Militärkommando in die Stadt gelegt wurde, konnte die Reform mit mehrjähriger Verspätung durchgesetzt werden. Wesentlich größere Unruhen gab es in Villingen. Hier dauerte der bürgerschaftliche Widerstand fast 30 Jahre mit Höhepunkten 1757/58, 1773/74, 1781/82 ${ }^{69}$. In Freiburg verband sich der zunächst von den Zunftmeistern geführte Widerstand gegen die neue Stadtverfassung mit Aufstandsbewegungen gegen den unbeliebten und ungeschickt agierenden Kreishauptmann von Schauenburg, die die Regierung mit militärischen Sanktionen beantwortete. Erst als Schauenburg 1762 abgelöst wurde, verebbten auch die gegen die neue Stadtverfassung gerichteten Unruhen ${ }^{70}$. In Breisach kam es zu Unruhen gegen die neueingesetzten Gremien, als deren Unfähigkeit und Korruptheit bekannt wurde ${ }^{71}$.

Diese Bewegungen machen deutlich, wie relativ begrenzt die Machtmittel noch des absolutistischen Staates für eine solche umfassende kommunale Verfassungsreform waren.

Ein wesentliches Element zur „Verstaatlichung“ der kommunalen Verwaltungsorganisation waren die Kreisämter, die es dem Staat ermöglichten, die bisherigen lokalen Zwischengewalten zu mediatisieren ${ }^{72}$. Bereits zwischen 1725 und 1729 hatte Kaiser Karl VI. Versuche unternommen, diese Kreisämter nach böhmischem Vorbild in den Vorlanden einzuführen, was aber teils aus personellen Gründen, teils wegen des massiven und konzentrierten Widerstandes der vorländischen Stände nur partiell gelang ${ }^{73}$. Unter Maria Theresia wurden die notwendigen organisatorischen Strukturen geschaffen, die jedoch - wie oben gezeigt - nur gegen teilweise erheblichen Widerstand durchgesetzt werden konnten. Mit der josephinischen Magistratsreform ab 1785 wurde das theresianische System weitgehend perfektioniert. Die Kommunen waren damit effektiv zu staatlichen Verwaltungsinstanzen unterer Ebene geworden ${ }^{74}$. Doch nicht nur organisatorische Reformen hatten den Erfolg dieser Maßnahmen bewirkt. Wesentlich war, daß es Österreich zwischen 1750 und 1780 gelang, einen

vgl. G. HeinRICH, Saatsaufsicht und Stadtfreiheit in Brandenburg-Preußen unter dem Absolutismus (1660-1806), in: Rausch (Hg.), wie Anm. 6, S. 155-172, hier S. 162

${ }^{69} \mathrm{~N}$. SCHLeicher, Die frühe Ratsverfassung der Stadt Villingen und der Kampf der Schnabulıner. Mordiner und Finkenreiter um das Stadtregiment, Konstanz 1873. S. 26-92.

${ }^{70} \mathrm{Vg}$. Quarthal, wie Anm. 41, S. 210f.; H. KOPF, Christoph Anton von Schauenburg. Freiburg 1978. S. 40-188.

71 HASElier, wie Anm 61, Bd. 2, S. 68-82.

72 Brunner, wie Anm. 20, S. 246; F. Dörrer, Probleme rund um die theresianische Kreıseıntellung Tirols, in: Besträge zur geschichtlichen Landeskunde Tirols. FS für F. Huter. hg. v. E. Troger/G. ZwaNowetz (Schlernschriften 207), Insbruck 159, S. 57-85, her S. 57: F. SundneR, Die Kreisämter als Vorlaufer politischer Behörden I.Instanz (1748-1848), in: J. GRëNDLER (Hg.), 100 Jahre Bezırkshauptmannschaften in Österreich, Wien 1970. S. 9-18; QuarthaL, wie Anm. 41, S. 47-55.

${ }^{73}$ Quarthal, wie Anm. 41, S. 65-82; DERS., wie Anm. 5, S. 288.

${ }^{74}$ Die josephınische Magistratsreform ist in den vorderosterreıchıschen Städten wesentlich einschneıdender empfunden worden als die theresianische Reform und hat deswegen in der lokalgeschichtlıchen Literatur eine umfängliche Beachtung gefunden. während die Maßnahmen von 1753-1756 häufig unbeachtet blıeben, bzw. mit den theresıanıschen Reformen zusammengeworfen wurden. Einen Überblick gibt SEIDLER, wie Anm. 40, S. 156-180. 
Beamtenstand heranzuziehen, der bereit war, sich voll dem Dienstgedanken des absolutistischen Staates zu unterwerfen. Nur durch den tiefgreifenden Mentalitätswandel in der Beamtenschaft - bis hinein in die Stadtmagistrate -- konnte der absolutistische Staat seine volle Wirksamkeit entfalten ${ }^{75}$. Durch Formung eines durch Bildung, Laufbahnvorschrift, Austauschbarkeit und Mentalität weitgehend homogenen Beamtenstandes konnte die "Verstaatlichung" weiter korporativ und genossenschaftlich geregelter Lebensbereiche in den Territorien des 18. Jahrhunderts durchgesetzt werden. Was zuvor in feudalem Sinn der persönliche Dienst und die persönliche Treueleistung für den Landesherrn gewesen war, entwickelte sich in der zweiten Hälfte des 18. Jahrhunderts zum Dienst an dem Staat. Der „allerhöchste Dienst“ wurde zu einer konkreten und realen Norm, an der der Einsatz der einzelnen Beamten gemessen wurde - lange vor dem berühmten „Hirtenbrief" Kaiser Josephs II., in dem er eine neue Gesinnung seiner Beamtenschaft in einer quasi religiösen Hingabe an den Staat forderte. Ohne diesen Mentalitätswandel der Beamtenschaft wäre die theresianische Reform zwischen 1750 und 1760 in Schwaben ebenso gescheitert wie die Maßnahmen Kaiser Karls VI. im ersten Drittel des 18. Jahrhunderts.

Erst seit 1756 bzw. 1785 waren die Kommunalverwaltungen in den habsburgischen Städten Südwestdeutschlands auf den modernsten Stand im Sinne absolutistischen Staatsverständnisses gebracht. Dann aber mußten Unterschiede zu der Praxis in Reichsstädten auffällig werden und bei unmittelbarer Nachbarschaft, die zu Vergleichen einlud, Kritik herausfordern.

In den kleineren südwestdeutschen Territorien änderten die Landesherren - zumindest nach dem bisherigen Forschungsstand - wenig an den äußeren Formen der Kommunalverfassung, sicherten sich jedoch einen maßgeblichen Einfluß auf die Verwaltung. Zugleich wurden wesentliche Kompetenzen den Kommunen entzogen und auf die Zentralbehörden übertragen. Durch strenge Aufsicht über alle Verwaltungshandlungen, insbesondere im finanziellem Bereich, war auch dort eine Integration in die absolutistische Verwaltung geglückt, auch wenn dort der Absolutismus stärker personell durch den jeweiligen Landesfürsten des Kleinterritoriums geprägt war ${ }^{76}$.

Stärker formalisiert war das staatliche Handeln in dem zweiten Großterritorium Südwestdeutschlands, in Württemberg. Die württembergischen Verhältnisse sollen nur noch skizziert werden. Auch hier waren die wenigsten Städte landesherrliche Gründungen, sondern sie waren durch Kauf, Heirat oder Verpfändung an das Territorium gefallen. Sehr viel früher als in den habsburgischen Besitzungen begannen hier Vereinheitlichungstendenzen ${ }^{77}$.

Im 15. Jahrhundert wurde das Gericht das tragende städtische Gremium; an die Stelle des häufig mit der Ehrbarkeit versippten Schultheiß trat ebenfalls im 15. Jahrhundert der landesherrliche Vogt ${ }^{78}$. Die Stadtrechte blieben im Prinzip unangetastet. Recht und Herkommen waren zumindest der Form nach Größen, die landesherrliches Handeln banden, auch wenn seit dem 16. Jahrhundert die Landesordnungen neues Recht schufen und über Wahlbeeinflussung und Kompetenzbeschneidung der

\footnotetext{
${ }^{75}$ Quarthal, wie Anm. 41, S. 86-102, 190-312.

${ }^{76}$ LEISER, wie Anm. 4, S. 130-134. Vgl. allgemein zur Eingliederung der Stadte in den Territorialstaat den Beitrag von Karl Czok, der allerdıngs die Entwicklung mehr als eınen Kampf der Fürsten gegen die landsässigen Stadte denn als einen staatlıchen EntwicklungsprozeB interpretiert (CzoK. wie Anm. 17. S. 21-42, hier S. 31-33).

${ }^{77}$ SeIGEL, wie Anm. 52, S. 177-193.

${ }^{78}$ Ders., wie Anm. 64, S. 14-43.
} 
landesherrliche Einfluß bis zum 18. Jahrhundert beständig wuchs. Die erste Kommunordnung von 1702 und die zweite von $1756^{79}$ setzten dann ein einheitliches Recht, auch wenn die Entmündigung der Kommunen bei weitem nicht so weit ging wie in Vorderösterreich unter Maria Theresia oder Joseph II. ${ }^{80}$. Im Gegenteil wurden dort im württembergischen Erbvergleich von 1770 kommunale Selbstbestimmungsrechte festgeschrieben ${ }^{81}$. Wichtig erscheint mir jedoch der Hinweis, daß die Entwicklung in Württemberg bisher nur im Rahmen der landesherrlichen Verordnungen verfolgt werden kann. Konkrete Untersuchungen im Rahmen einzelner Städte fehlen bislang, so daß die Entwicklung vielleicht glatter aussieht als sie im historischen Verlauf wirklich war.

In einem Zusammenhang mit den landesherrlichen Veränderungen von Stadtverfassung und Stadtverwaltung landsässiger Städte möchte ich ein Phänomen in den Reichtsstädten stellen, das lange Zeit unter negativem Vorzeichen gesehen wurde: ich meine die Bürgerunruhen und die daraus entstehenden Reichshofratsprozesse ${ }^{82}$. Johann Jakob Moser, der von 1650 bis 1770 Beispiele solcher Prozesse in 30 Städten anführt, urteilte darüber aufgrund seines auf Ausgleich bedachten Staatsverständnisses: „Wann die Magistrate und Bürgerschaften so klug wären und bald anfangs überlegten, was dergleichen Prozesse und die daraus entstehende, auch darauf erfolgende Commissionen und militärische Executionen kosten, wurden sie auch so klug seyn und sich lieber bald Anfangs mit einander vergleichen.“ Mit diesen Konflikten haben sich in den letzen Jahren Karl Czok ${ }^{83}$, Klaus Gerteis ${ }^{84}$, Reinhard Hildebrandt ${ }^{85}$, und Jean Francois Noel ${ }^{86}$ beschäftigt. Die Tendenzen der reichshof rätlichen Rechtssprechung sind deutlich: Bewahrung der obrigkeitlichen Rechte des Rates, die Betonung der Teilhabe der Bürgerschaft an der Vertretung der Reichsstandschaft, und der Versuch, Mißbräuche, namentlich finanzielle Gebrechen, abzustellen.

\footnotetext{
${ }^{79}$ SPECKER, wie Anm. 52, S. 1-21.

${ }^{80}$ Generalverordnung von 1702 (A.L. REYSCHER, Sammlung der württembergischen Gesetze, Bd 13. Tübıngen 1851, S. 755-804), ..Commun-Orónung" von 1758 (REYSCHER, Bd. 14, S. 537-777).

81 Ebd., S. 15.

82 Zu den Reichshofratsprozessen vgl Moser, wie Anm. 14, S. 427-468; O. voN GSCHLIESSER, Der Reichshofrat. Bedeutung und Verfassung. Schicksal und Besetzung eıner obersten Reichsbehörde von 1559 bis 1806, Wien 1942; W. Sellert, Prozeßgrundsätze und Stilus curıae am Reıchshofrat im Vergleich mit den gesetzlichen Grundlagen des reichskammergerichtlichen Verfahrens (Untersuchungen zur deutschen Staats- und Reichsgeschichte NF 18), Aalen 1973; Bader, wie Anm. 2, S. 56, 64; CzOK. wie Anm. 17, S. 21-42, hıer S. 29; zuletzt V. PRESS, Die Reschsstädte des schwäbischen Reichskreises zwischen Revolution und Mediatisierung. in: Katalog der Ausstellung ..Baden und Wuirttemberg im Zeıtalter Napolcons“. Stuttgart 1987. S. 121-135. Zur Reflexıon der Bürgerunruhen in der zeitgenössıschen reıchsstädıschen Histonographie vgl. ScHURIG, wie Anm. 29, S. 260-262.

$8.3 \mathrm{Vgl}$. Anm. 63.

${ }^{4} \mathrm{~K}$ GERTE1S, Repräsentation und Zunftverfassung. Handwerkerunruhen und Vefassungskonflikte in südwestdeutschen Städten vor der Franzosischen Revolution, in: ZGO 122 (1974), S. 275-287, DERS . wie Anm. 17. S. 43-58.

85 Huldebrandt, wie Anm. 17, S.221-241, DERS. Zur Frage der reıchsstädtischen Finanzen und Haushaltspolıtık seıt dem Westfäıschen Frıeden, in - E. MASCHKE/J. Sydow (Hgg.), Städtisches Haushaltsund Rechnungswesen (Stadt in der Geschichte 2), Sigmaringen 1977. S. 91-107.

s6 NOEL. Wie Anm 18, S. 121-131
} 
Stellt man jedoch die wenigen gut untersuchten Beispiele reichshofratlicher Tätigkeit zusammen - Augsburg ${ }^{87}$, Ulm ${ }^{88}$, Rottweil ${ }^{89}$, Reutlingen ${ }^{90}$, Isny ${ }^{91}$ - so wird offenbar deutlich, da $B$ es um weit mehr als Rechtssprechung geht. Den Urteilen ging in der Regel eine intensive Bestandsaufnahme des gesamten Stadtzustandes voraus. Die Tätigkeit des Reichshofrates war zu guten Teilen eher eine administrative denn einen jurisdiktionelle. So mußte die Reichsstadt Ulm dem Reichshofrat um 1770 einen ausführlichen Bericht über die städtischen Aktiva und Passiva, zusammen mit ausgearbeiteten Verbesserungsvorschlägen, einreichen, bevor ihr die Veräußerung städtischer Realien gestattet wurde ${ }^{92}$. Über das weitere Vorgehen mußte die Stadt regelmäßige Jahresberichte nach Wien senden, in denen das Finanz- und Verwaltungsgebaren Ulms überprüft wurden. In Fragen der Besoldungsregelung in Heilbronn, Schweinfurt und Dinkelsbühl nahm der Reichshofrat nahezu die Funktion einer landesherrlichen Oberbehörde ein. Jean Francois Noel sprach von einem „halb gerichtlichen, halb administrativem Verfahren ${ }^{93}$. Die Modernisierung der städtischen Verwaltung und Rechnungsführung - etwa im Fall von Isny - wurde im Auftrag des Reichshofrates vorgenommen.

Seine Entscheidungen hatten - wie sich an Isny und Rottweil zeigen läßt - Verfassungscharakter wie das Stadtrecht. Über Lokal-und Hofkommissionen konnte der Reichshofrat intensiv in das innerstädtische Leben eingreifen.

Eine bekannte Tatsache ist es, daß das Reich keine Unterbehörden hatte, und da $B$ die Kreise seit dem 17. Jahrhundert teilweise in diese Funktion hineingewachsen sind. Eine besondere Rolle fiel dabei den kreisausschreibenden Fürsten zu. Ihre Tätigkeit als kaiserliche Kommissare, die seit dem späten 17. Jahrhundert einen breiten Raum einnahm - in Form der Subdelegationskommission -, ist trotz einer breiten archivalischen Überlieferung für Südwestdeutschland so gut wie nicht untersucht, worauf unlängst Raimund Weber hingewiesen hat ${ }^{94}$.

Durch die Tätigkeit landesfürstlicher Beamter als Subdelegationskommissare ist in vielen Fällen der Modernisierungsschub der landesherrlichen Verwaltung namentlich im Finanzwesen an die Reichsstädte weitergegeben worden.

Reichsstädte stehen im Ruf, eine überteuerte Verwaltung gehabt zu haben ${ }^{95}$. Dort, wo dies nachprüfbar ist -- etwa im Falle Isnys - scheint dies im Vergleich mit landesfürstlichen Verwaltungen oder landsässigen Städten nicht unbedingt zu stimmen. Isny hatte zwischen 1777 und 1785 Personalausgaben in Höhe von rund 3700 fl., wobei der graduierte Stadtschreiber rund 500 fl. erhielt ${ }^{96}$. Auf diese Summe

${ }^{87}$ BÁTORI, Wie Anm. 32

${ }^{88}$ GÄNSSLEN, wie Anm. 32, S. 120-202.

${ }^{89}$ A. LALFS, Verfassung und Verwaltung der Stadt Rottwell 1650-1806 (VKomLk in Baden-Wurttemberg B 22), Stuttgart 1963.

${ }^{90}$ S. STÄHLE. Verfassung und Verwaltung der Reichsstadt Reutlıngen zwischen 1740 und 1770 Aspekte reichsstädtischer Geschıchte im 18. Jahrhundert. in: Reutlınger Geschıchtsblatter NF 23. (1984), S 7 207.

${ }^{91} \mathrm{C}$.-H. Hauptmeyer, Verfassung und Herrschaft in Isny. Untersuchungen zur reichsstadtischen Rechts-. Verfassungs- und Sozalgeschichte, vornehmlıch in der Neuzelt (Goppınger Akademische Beıtrage 97). Göppingen 1976.

92 GäNSSLEN, wie Anm 32, S 120 .

${ }^{93}$ NOEL, wie Anm. 18, S 124.

${ }^{94}$ R.J. WEBFR, Die kaiserlichen Kommissionen des Hauses Wurttemberg in der Neuzert, in ZWurttLG 43 (1984), S. 205-236; für Reutlıngen vgl. STÄHLE, wie Anm. 90, S. 66-96.

95So zusammenfassend GerTEIS, wie Anm. 5. S. 91.

96 SPETH, wie Anm 37, S 147-149. 
kamen vergleichbare landesfürstliche Städte auch. Für einen promovierten Juristen war diese Summe zu Ende des 18. Jahrhunderts keine exorbitante Bezahlung.

Auch reichsstädtische Verwaltungen und Verfassungen wandelten und modernisierten sich während des 17 . und 18. Jahrhunderts. Wie in den landsässigen Städten kam der Druck dazu von außen. Im Unterschied zur systematischen Tätigkeit landesherrlicher Verwaltung blieb das Reich gegenüber den Reichsstädten auf einer altertümlichen Stufe stehen: Die Tätigkeit des Reichshofrates glich der intermittierenden Territorialverwaltung des 16. Jahrhunderts, obwohl auch hier Übergangsformen festzustellen sind, wenn etwa der Rat die Finanzverwaltung und das Steuerwesen über einen langen Zeitraum an den Reichskreis abtreten mußte. Auf jeden Fall muß man, um das Verhältnis Kaiser - Reichshofrat - Reichsstadt besser zu beurteilen, weniger den jurisdiktionellen Aspekt der Reichshofratsentscheidung, sondern ihre administrative Funktion herausstellen.

In der Beurteilung des Erfolges reichshofrätlicher Maßnahmen wird oft betont, $\mathrm{da}$ sie erfolglos gewesen seien, weil sich nach 15 oder 20 Jahren die gleichen Mißstände gezeigt hatten. Ich meine jedoch, aus der zeitgenössischen Situation gesehen, sind 20 Jahre eine lange Zeit, die eher für eine erfolgreiche Tätigkeit spricht.

Dem Konzentrationsprozeß der Territorien und deren Integration der Städte in die Territorialverwaltung folgte das Reich über den Reichshofrat und die Kreiskommissionen zwar abgeschwächt, aber doch spürbar, wenn auch in antiquierten Formen. Der Kaiser als Stadtherr war in den Reichsstädten seit dem 18. Jahrhundert keine Leerform ${ }^{97}$; in seinem Verhältnis zu den Reichsstädten nahm er teilweise landesherrliche Züge an, so sehr, daß man in der zweiten Hälfte des 18. Jahrhunderts die Tätigkeit der Magistrate als Auftragsverwaltung für den Kaiser interpretiert hat ${ }^{98}$.

Wesentlich aber erscheint die Tatsache, daß Schuldenkrisen, Oligarchisierung der Verwaltung, Bürgerunruhen in landesherrlichen wie in Reichsstädten im 17. und 18. Jahrhundert gleichermaßen auftraten. Es gab in dieser Periode eine Krise städtischer Existenz, die bei den Reichsstädten nur deswegen so manifest wurde, weil Remeduren nur über ein Eingreifen von außen möglich waren. Die wirtschaftliche Krise der Städte nach dem Dreißigjährigen Krieg war allgemein, in Südwestdeutschland wurde sie verstärkt durch den Ausfall der traditionellen Handelspartner in Norditalien seit der gleichen Zeit. Die Territorialisierung des Gewerbes, der Verfall des neckarschwäbischen Weinhandels, die Präponderanz Norddeutschlands im geistigen Leben, die enorme Kriegsbelastung des südwestdeutschen Raumes bis ins erste Drittel des 18. Jahrhunderts und dann ieder seit 1756, dazu die Belastung durch die hohe strukturelle Arbeitslosigkeit dieses Raumes, die Konkurrenz durch die wirtschaftlich agile Schweiz in der neuen Arbeitsform, der Manufaktur, und der modernen Vertriebsform, dem Verlag, das Fehlen einer wirklich großen Territorialmacht, die in der Hochphase des absolutistisch und kameralistisch geprägten Zeitalters Impulse in Südwestdeutschland hatte setzen können, all dies führte die im Grund mittelalterlich strukturierten Städte dieses Raumes in eine soziale und ideelle Krise. Im Territorium gab es durch die absolutistisch geprägte Regierungsspitze eine Kraft, die gegen beharrende Kräfte eine Veränderung aufzwingen konnte. $\mathrm{DaB}$ dabei die Verbesserung wirtschaftlicher Rahmenbedingungen und strukturelles

\footnotetext{
${ }^{97}$ Im Gegensatz dazu sah K.S. BADER enn .merkwürdig gehemmtes Verhältnıs der Reichsstädte zum Reich" und sprach von einer. .Abwehrhaltung G. J. auf Katser und Reich". (BAdER, wie Anm. 2. S 66) ${ }^{98}$ Hildebrandt, wie Anm. 17, S. 240.
} 
Machtinteresse absolutistischer Herrschaft unter Hintansetzung gewachsener Privilegien und genossenschaftlicher Selbstbestimmung Hand in Hand gingen, steht außer Frage. Territorium und Stadt waren jedoch in dieser historischen Situation aufeinander angewiesen. Es kann kein Zweifel bestehen, da B ,landesfürstliche Städte aus staatlicher Einordnung neue Lebenskräfte zur Förderung des Wohlstandes, Handels und Gewerbes zogen“" 99 . Landesherrliche Städte wurden von außen gezwungen, mit den Entwicklungen des modernen Rechts- und Verfassungslebens Schritt zu halten ${ }^{100}$. Auf Territorium und Stadt lastete durch die wirtschaftliche Veränderung gleichermaßen ein externer Druck zur Veränderung, doch nur die Territorien besaßen die Instrumentarien, ihre Städte zur nötigen Anpassung zu zwingen.

Eine wesentliche Aufgabe des 18. Jahrhunderts war es, die auf Grund von Privilegien, Herkommen und oligarchischer Abschließung besetzten Führungsgremien der Städte in einem Rationalisierungsproze $B$ durch qualifizierte und in den modernen Bildungssystemen bewährte Beamte und Gremien zu ersetzen. Daß dabei durchaus gleichwertige Normen wie Selbstbestimmung, Wahlrecht, soziale Vernetzung hintangesetzt wurden, steht außer Frage. Der gemeine Nutzen wurde weitgehend an Effizienz und finanziellem Ertrag gemessen. Verwaltungsreformen gelangen also Städten der Territorialstaaten des 18. Jahrhunderts nur durch Eingriffe von außen. Die Reichsstadt war in der Territorialstruktur des 18. Jahrhunderts ein antiquiertes, keineswegs jedoch statisches Gebilde. Mangels ausgebildeter institutioneller Wege konnten Neuerungen dort nur auf dem Wege über Bürgerunruhen, kaiserliche und reichshofrätliche Eingriffe geschehen.

Bislang hat man die Bürgerunruhen in den Reichsstädten des 18. Jahrhunderts mit Blick und im Vergleich zu den Ereignissen des revolutionären Frankreichs bewertet. Ein Interpretationsmodell, daB Reichs- und Territorialstädte einander annähert, das im Kaiser einen „Landesherrn“ der Reichsstädte sieht, der mit antiquierten Methoden reagieren mußte und der über Quasi-Verwaltungsinstrumente wie Reichshofrat, Subdelegatskommission und Debitkommission unter pfleglicher Wahrung traditioneller Rechtszustände eine Modernisierung von Sozialstruktur, Wirtschaft, Verwaltung und Verfassung der Reichsstädte erreichen wollte und sich dabei des Modernisierungsvorsprungs der Reichsstände durch die Übertragung von Kommissionen auf deren Beamte bediente, dies erscheint mir für die historische Realität schlüssiger zu sein als bisherige Deutungen. Da diese Modernisierung in den Reichsstädten jedoch nur mit Verzögerung gegenüber den Territorien erfolgte, ist ein Nachweis einer Effizienz dieser Reformen in vielen Fällen wegen der baldigen Mediatisierung der Reichsstädte nur in wenigen Fällen zu erbringen ${ }^{101}$. Über Ulm beispielsweise brach die Mediatisierung 1802 mitten in Verhandlungen zwischen Rat und Bürgerschaft unter Vermittlung des kaiserlichen Ministers beim Schwäbischen Kreis herein; ein vom

\footnotetext{
${ }^{99}$ Hubatsch, wie Anm. 33, S. 35

100 Ebd.

101 Verwiesen sei nochmals auf den Tenor alterer Darstellungen, wo es hieB ..Langst hatten die Reıchsstädte ihre Zeit erfüllt. Alt und morsch geworden, wurden sie von den St ürmen der napoleonuschen Kriege hinweggefegt. Ruhmlos fielen sie Mächten zum Opfer, die im Laufe der Jahrhunderte stärker geworden waren als sie selbst 'Die Länder, nicht die Stadtstaaten wurden das Ruckgrat der deutschen Staatsentwicklung". (E. Schell, Die Reichsstadte beim Ubergang an Baden. Heidelberg 1929, S. 14).
} 
Ratskonsulenten Holl vorgelegter demokratischer Verfassungsentwurf konnte weder beschlossen noch konnte seine Realisierbarkeit getestet werden ${ }^{102}$.

Sicher ist die Verwaltung der Reichsstädte nicht das, was ihre Bedeutung ausmacht. Otto Borst hat in seinem grundlegenden Aufsatz die kulturelle Leistung der Reichsstädte auch für die Zeit nach 1550 als ihren eigentlichen Beitrag zur Geschichte Südwestdeutschlands in der Neuzeit herausgearbeitet ${ }^{103}$. Und nicht zuletzt war auch das Reichsbewußtsein, das von ihnen getragen wurde, ein wichtiges Element für die Existenz dieses Reiches ${ }^{104}$. Im Blick reichsstädtischer Historiographen waren die Reichsstädte für den Kaiser „opes et robur Imperii, ja welche man mit Fug als edle Kleinodien der kaiserlichen Kron ansehen mag" ${ }^{105}$. Das Kaiserhaus galt für die Geschichtsschreiber als ,die Pffegemutter mindermächtiger Reichsstände, absonderlich der Reichsstädte, die Grundveste des Reichs, die Haupt und Glieder durch Jahrhunderte hin in dieser Verfassung glücklich befestigt hat“ ${ }^{106}$. Jede Anstrengung zur Erhaltung der Reichsstädte war zugleich ein Dienst am Reich. Dies erklärt das Bestreben reichsstädtischer Geschichtsschreibung, den Konnex mit Kaiser und Reich herauszustellen und die Existenz der Reichsstädte mit historisch fundierten Argumenten zu verteidigen. Auf der anderen Seite kann die reichshofrätliche Tätigkeit in der zweiten Hälfte des 18. Jahrhunderts, die ihren Rückhalt im Kaiser hatte, als Bemühung des Reichsoberhauptes verstanden werden, mit den Mitteln, die die Reichsverfassung bot, einen Beitrag zur Bewahrung der kleinen Reichsstände und der Reichsstädte gegenüber den Territorien zu leisten.

Beide Bemühungen sind gescheitert. Das Bindeglied zum Mittelstaat des 19. Jahrhunderts war das Territorium, nicht das mit unzureichenden Mitteln um Reform bemühte Reich. Um so anrührender ist die Passage in der Denkschrift des Rottweiler Bürgermeisters Hofer, die er 1802 ,namens der freien Reichsstädte in Schwaben" der Reichsdeputation in Regensburg übergab, in der er die Selbstaufgabe der Reichsstädte als Mittel zum Fortbestehen des Reiches erklärte: „So empfindlich ihnen dieses unverschuldete Schicksal ist, [...] so wollen doch diejenigen Reichsstädte in Schwaben, welche ausersehen sind, dieses letzte Opfer, sofern es zur eigentlichen Beruhigung des deutschen Vaterlandes unvermeidlich ist, auch noch bringen und dadurch beweisen, daß unser den von ihren Vorfahren auf sie gekommen echt reichsstädtische Tugenden, Vaterlandsliebe und Liebe zum Wohl des Ganzen, sie vorzüglich zu beseelen“" 107 .

Mit den Reichsstädten ging das Reich unter, wie dies aus einer eindrucksvollen Stelle aus einem Schreiben der Frau Rath Goethe an ihren Sohn vom 19. August 1806 hervorgeht. Sie schrieb dort: „Mir ist übrigens zumuthe als wenn ein alter Freund sehr kranck ist, die Ärzte geben ihn auf, mann ist versichert daß er sterben

${ }_{102}$ Gänssles, wie Anm. 32, S. 127-142.

${ }^{103} \mathrm{Vgl}$. O. BoRst, Die geistıgen und politischen Traditıonen der Reschsstadt Esslingen am Ende des alten Reıches, in: Esslinger Studien 1 (1956), S. 43-55.

$104 \mathrm{Vgl}$. H.J. Herbig, Kaisertum und Reichsstadt. Eine Studie zum dynastıschen Patriotısmus der Reichsstädte nach dem Westfalischen Frieden bis zum Untergang des Reiches. in MVGNurnberg 58 (1971). S. $211-268$.

${ }^{105}$ E. Roth, Histona Universalıs Pragmatica, Ulm 1706, S. 2f. (zit. nach Schlrig, wie Anm. 29. S 228)

106 J.F. SçöpperLIN, Von der Römischen Königswahl, in: DERS., Kleıne histonsche Schriften, Bd. 1. Nördlingen 1782, S. 30, (zit. nach SchurıG, wie Anm. 29, S. 294).

${ }^{107}$ Die J.B.-Hofer-Denkschrift Namens der freien Reichsstädte in Schwaben 1802 überreicht beı der Reichsdeputation zu Regensburg. (hg. v. E. MACK), Rottwell 1926, (21t. nach SCHlrig. wie Anm 29. S 2961 
wird und mit all der Gewißheit wird man doch erschüttert wann die Post kommt er ist tot. So gehts mit und der gantzen Stadt. Gestern wurde zum ersten mahl Kaiser und Reich aus dem Kirchengebet weggelassen" ${ }^{108}$.

Dieser Brief stammt mit gutem Grund aus einer Reichsstadt. Trotz aller Reformbemühungen hatten die in der Reichsverfassung eingebetteten Reichsstädte bis auf wenige Ausnahmen nicht den Weg in die Staatlichkeit des 19. Jahrhunderts gefunden. Obwohl den Landstädten in ihrer Verfassungsform nur wenig unterlegen, zählte die Reichsstadt neben den reichsfreien Abteien und der Reichsritterschaft zu den Verlierern bei der Reichsreform von 1803 und bei dem schließlichen Untergang des Reiches im Jahre 1806.

\footnotetext{
108 Wesentlich kritıscher das Urtel K.S. Baders. „Die Reıchsstadte von 1800 vermochten jedenfalls dem Heiligen Römıschen Reıch nıchts mehr zu geben. was Kraft und staatlıche Geltung bedeutet hatte Sie waren reif für den Untergang." (wie Anm. 2, S. 70)
} 